Vol. 2: (December ) 2012

\title{
Hak Asasi Manusia (Human Rights) dalam Menangani Krisis Alam Sekitar: Perspektif Seyyed Hossein Nasr
}

\author{
Human Rights in Dealing with the Environmental Crisis: \\ Seyyed Hossein Nasr's Perspective
}

ZUL `AZMI YAAKOB* \& ZAILAN MORIS ${ }^{1}$

\begin{abstract}
'Human rights' are the basic rights and fundamental freedoms. Today's human rights movements also concern on nature in resolving the environmental crisis. Within the freedom of thought and expression, this trend has extended dramatically in recent years, as many people have been surrounded by massive pollutions such as global warming and water crisis. Many environments have been greatly altered by human activities. On the right track, scholars and scientists have taken risks to test so many ideas and approaches that could lead to exponential changes to improve or even preserve the natural environment. Although 'human rights' has been used popularly in recent decades, Seyyed Hossein Nasr argues that the term should be blamed for the environmental crisis we are presently facing. As one of the most important and foremost Muslim philosophers in the world today, Nasr emphasizes that the environmental crisis is created by the crisis of human value in their philosophy of human rights based on human 'freedom'. Nasr's writings on human rights can be observed in his Islam and the Environmental Crisis (1990), Islam and the Challenge of the 21 $1^{\text {st }}$ Century (1993) and Religion and the Order of Nature (1996). This semantic study is to show that human rights' philosophy is too dangerous to nature, tracking on the unconditional absolute rights. Through semantic analysis, the study finds that 'human rights' are related to secular philosophy which enthrones the unlimited human freedom, and at the same time against the order of nature as Divine Order.
\end{abstract}

Keywords: human rights, environment, Islam, Nasr.

Manusia secara mudah dikategorikan sebagai penyumbang utama kepada krisis alam sekitar di samping faktor bencana alam. Ini ditambah pula kejadian bencana alam seperti banjir kilat, tanah runtuh dan kebakaran hutan, yang hakikatnya turut disumbangkan secara tidak langsung oleh aktiviti manusia yang tidak terkawal. Isu ini telah menarik perhatian banyak pihak termasuklah badan-badan kerajaan dan bukan kerajaan (NGO) dalam bersama-sama memperjuangkan masa depan alam sekitar. Ada yang menyuarakannya melalui pendidikan, undang-undang, politik, malah tidak ketinggalan juga yang melaungkan kepentingan menjaga alam sekitar melalui kempen dan aktiviti-aktiviti

${ }_{1}^{1}$ Zulazmi Yaakob*(Corresponding author), M.A., Lecturer at the Department of Theology and Philosophy, Universiti Kebangsaan Malaysia, 43600 Bangi, Selangor, Malaysia. Email: zulazmi@ukm.my. Zailan Moris, Ph.D. Professor at the School of Humanities, Universiti Sains Malaysia, 11800 Pulau Pinang, Malaysia. Email: zailan@usm.my.

https://doi.org/10.24035/ijit.2.2012.008 
mesra alam. Permasalahan alam sekitar turut mendapat tempat di kalangan pendukung hak asasi manusia (human rights).

Dalam konteks global, isu alam sekitar telah menjadi perkara utama bagi Pertubuhan Bangsa-bangsa Bersatu (United Nations) melalui agensinya Program Alam Sekitar Pertubuhan Bangsa-bangsa Bersatu yang dikenali sebagai 'United Nations Environment Programme' (UNEP). Melalui kekerapan perbincangan dan kerjasama dengan Pejabat Pesuruhjaya Tinggi Hak Asasi Manusia iaitu 'Office of the High Commissioner for Human Rights' (OHCHR), maka fokus hak asasi manusia telah diperluaskan kepada mewujudkan suasana masyarakat yang prihatin tentang pentingnya alam sekitar yang selamat demi memastikan kehidupan mereka menjadi lebih bermakna, menyihatkan dan penuh lestari (United Nations Environment Programme t.th: 1). Maka, ini akan meluaskan lagi konsep dan skop 'hak asasi manusia' bagi membuktikan ia turut terlibat dalam usahausaha menyelamatkan alam sekitar. Kerjasama antara UNEP dengan OHCHR memberikan harapan yang tinggi tentang betapa pentingnya tahap kesedaran masyarakat demi memastikan alam semula jadi dapat dikekal kewujudannya dan dibaik pulih kerosakannya.

Pada tahun 2002, terdapat satu perbincangan utama yang melibatkan pihak UNEP dan OHCHR serta turut dihadiri oleh golongan pakar, sarjana, pentadbir dan saintis. Hasil daripada perbincangan tersebut, masih banyak langkah kehadapan yang perlu diambil perhatian oleh pihak OHCHR. Bagi memastikan alam semula jadi dapat dipertahankan kewujudannya di samping dapat dibaik pulih pencemarannya, maka langkah-langkah yang perlu dilaksanakan termasuklah:

- Mempertingkatkan kesedaran masyarakat terutama sekali melibatkan sektor korporat dalam melindungi alam sekitar.

- Tidak dikenakan sebarang tindakan ke atas mana-mana individu yang aktif mempromosi dan yang mempertahankan secara lantang kepentingan melindungi alam sekitar.

- Memperjelaskan kepentingan menjaga alam sekitar di peringkat kebangsaan dan antarabangsa secara berterusan dengan mempermudahkan kaedah capaian maklumat mengenainya.

- Memperkasakan hubungan secara langsung antara 'hak asasi manusia' dengan 'perlindungan alam sekitar' sebagai satu set utama ataupun pasangan yang tidak boleh dipisahkan dalam segala aktiviti membasmi kemiskinan dan mencapai pembangunan serta kemajuan.

- Membentuk satu kesepaduan aktiviti berperaturan yang menggabungkan antara ekonomi, hak asasi manusia, pelestarian alam sekitar dan penguatkuasaan undangundang, sekaligus meletakkan kedudukan alam sebagai isu penting dan serius.

- Sentiasa berkempen dan mempromosi tentang kebahagiaan kehidupan yang lebih menyihatkan, iaitu dengan menjelaskannya bahawa semua itu hanya boleh dinikmati sekiranya suasana alam sekitar berada dalam keadaan tidak tercemar.

- Menerbitkan segala bentuk maklumat berhubung kepentingan menjaga alam sekitar sama ada melalui media cetak mahupun elektronik (Office of the High Commissioner for Human Rights 2002: 3-4).

Perjuangan OHCHR melalui tiket human rights tentang kepentingan menjaga alam sekitar telah memberikan kefahaman yang menarik mengenai 'hak asasi manusia'. Memastikan manusia berhak mendapatkan persekitaran yang menyihatkan, merupakan salah satu sebab mengapa alam semula jadi perlu dipertahankan. Satu persidangan yang dianjurkan pada tahun 1972 oleh Pertubuhan Bangsa-bangsa Bersatu (UN) telah 
menjelaskan bahawa isu alam sekitar semakin mendapat tempat dalam human rights. Ini dinyatakan:

The many linkages between protection of human rights and protection of the environment have long been recognized. The 1972 United Nations Conference on the Human Environment declared that "man's environment, the natural and the man-made, are essential to his well-being and to the enjoyment of basic human rights - even the right to life itself" (Office of the High Commissioner for Human Rights 2007: 1).

Oleh demikian, peranan OHCHR dalam meluaskan slogan 'hak asasi manusia' terhadap usaha-usaha menyelamatkan alam sekitar tidak boleh diperkecilkan. Nampaknya konsep 'hak asasi manusia' bukan lagi semata-mata melibatkan kedudukan setiap manusia, tetapi turut melibatkan kedudukan setiap bahagian alam. Sebarang perkara yang merosakkan alam sekitar, maka ia membawa maksud kepada pelanggaran 'hak asasi manusia'. Contohnya, perubahan iklim telah dikenal pasti sebagai salah satu pelanggaran 'hak asasi manusia'. Walaupun ia dirasakan kurang sepadan untuk dikaitkan dengan 'hak asasi manusia', namun kemerosotan kualiti alam sekitar sehingga menyebabkan diri masyarakat semakin rimas dan tidak selesa menghadapi persekitaran sedemikian, menunjukkan hak dan kebebasan manusia bagi mendapatkan kehidupan yang nyaman, damai dan menyihatkan telah dicabuli.

Kajian dari Massachusetts Institute of Technology (MIT) menunjukkan, suhu yang tinggi telah menyebabkan corak hujan yang melampau di kawasan tropika. Setiap peningkatan suhu sebanyak satu darjah Celsius di kawasan tropika, maka akan meningkatkan kadar hujan yang melampau sebanyak 10 peratus. Ini memberikan kesan yang buruk di kebanyakan kawasan tropika yang padat penduduknya (Foon Weng Lian 2012: 1). Terdapat tiga perkara utama yang dikaitkan dengan alam sekitar dan sepatutnya dibimbangkan oleh masyarakat dalam memastikan mereka tidak kehilangan hak asasinya. Pertama sekali adalah hak kepada air. Kedua pula adalah hak kepada makanan manakala akhir sekali adalah hak kepada kesihatan. Saban hari masyarakat semakin kehilangan sumber air yang bersih di samping kerap mengalami kemarau dan banjir yang melampau. Ini juga menyumbang kepada kemusnahan sumber tanaman dan bahan mentah yang lain. Dijangka seramai 50 juta penduduk dunia akan mengalami kebuluran pada tahun 2020, malah mungkin meningkat kepada 200 juta menjelang tahun 2080. Akibat daripada keadaan serba kekurangan dan tidak bersistem sedemikian, maka semua ini menyumbang kepada kemerosotan kualiti kesihatan penduduk dunia seperti serangan penyakit malaria dan demam denggi (Azwani Abdul Rahman 2010: 1). Betapa besar kesan negatif yang bakal dialami oleh manusia sekiranya ketiga-tiga 'hak asasi manusia' tersebut sudah tidak lagi dimiliki.

\section{Human Rights (Hak Asasi Manusia) menurut Seyyed Hosein Nasr}

Dalam keghairahan masyarakat memperjuangkan 'hak asasi manusia' dan kepentingannya menangani krisis alam sekitar, didapati keadaan krisis tersebut kian meruncing sama ada dalam konteks kebangsaan mahupun antarabangsa. Sumber air menjadi semakin tercemar, hutan simpan semakin berkurangan manakala pemanasan global kian dirasai di serata tempat yang dihuni oleh manusia. Adakah semua ini menunjukkan pendukung 'hak asasi manusia' gagal melaksanakan tugasan mereka dengan baik sebagai masyarakat yang 
bertanggungjawab? Atau mungkinkah semua ini menunjukkan masyarakat sekeliling masih lagi gagal memahami tentang konsep dan skop 'hak asasi manusia' yang hakiki?

Bagi persoalan ini, Seyyed Hossein Nasr yang merupakan seorang ahli falsafah Islam mutakhir ada jawapannya. Sebagai seorang ahli falsafah dari Iran yang kini telah menetap di Amerika Syarikat, Nasr telah memerhatikan suasana 'hak asasi manusia' begitu cukup lama khususnya di Amerika Syarikat yang terkenal dengan pelbagai pertubuhan bersifat human rights (hak asasi manusia). Beliau sendiri sebenarnya mempunyai keraguan terhadap falsafah yang terkandung dalam slogan ataupun kata kunci human rights. Ilmu makna ataupun semantik bagi istilah human rights didapati mempunyai nilai yang berlainan jika dikaji secara mendalam berdasarkan analisis ke atas pemikiran Nasr. Justeru, kajian ini cuba menilai aspek semantik human rights yang dibahaskan oleh Nasr, yang secara tidak langsungnya dikaitkan dengan isu alam sekitar. Perbahasan Nasr tentang sesuatu isu begitu kerap melibatkan aspek semantik, malah ini pernah diakui oleh sarjana Barat Kurt A. Wood yang mengulas: ". . . Nasr is notable as one who has addressed various facets ... He identifies a semantic problem in discussing 'science' and Islam" (Wood 2006: 98-99).

Dalam Kamus Dewan, perkataan 'hak asasi manusia' tidak ada dinyatakan dalam satu bentuk kosa kata. Perkataan-perkataan tersebut hanya diletakkan secara berasingan iaitu kepada tiga perkataan. Perkataan 'hak' dimaknakan sebagai 'kuasa' atau 'kepunyaan'. Ia juga boleh diseertikan sebagai 'kebenaran'. Perkataan 'asasi' pula dimaksudkan sebagai 'menjadi dasar' ataupun 'yang menjadi pokok', berasal daripada perkataan 'asas' yang bermaksud 'alas', 'dasar', 'tapak' atau 'sesuatu yang menjadi sandaran'. Untuk perkataan 'manusia', ia diistilahkan dalam Kamus Dewan sebagai 'makhluk yang mempunyai akal budi', 'insan' ataupun 'orang' (Noresah Baharom 2007: 82, 500 \& 997). Melalui gabungan ketiga-tiga perkataan tersebut, secara umumnya 'hak asasi manusia' boleh difahami sebagai 'kuasa asas yang dimiliki oleh setiap individu berdasarkan kelebihan masing-masing yang bertujuan memastikan dirinya berpeluang mendapat kehidupan yang lebih baik dan saksama'.

Secara dasar, OHCHR menjelaskan maksud human rights dalam suasana yang menunjukkan bahawa setiap manusia mempunyai hak dan kelebihan masing-masing untuk diberikan peluang dan perlindungan yang sewajarnya selagi mana ia dikehendaki. Jelasnya:

Human rights may be generally defined as those rights which are inherent in our nature and without which we cannot live as human beings. Human rights and fundamental freedoms allow us to develop fully and use our human qualities, our intelligence, our talents and our conscience and to satisfy our spiritual and other needs. They are based on humankind's increasing demand for a life in which the inherent dignity and worth of each human being are accorded respect and protection. Their denial is not only an individual and personal tragedy but also creates conditions of social and political unrest, sowing the seeds of violence and conflict within and between societies and nations (Office of the High Commissioner for Human Rights 2004: 6).

Dengan kata lain, human rights diperjuangkan adalah untuk membela nasib setiap manusia agar sentiasa diberikan ruang kebebasan dan perlindungan, malah perlu dihormati haknya daripada menjadi mangsa diskriminasi oleh pihak-pihak tertentu dalam segala aspek. Dari sudut falsafah iaitu merujuk kepada Stanford Encyclopedia of Philosophy, perkataan human rights dihuraikan: 
Human rights are international norms that help to protect all people everywhere from severe political, legal, and social abuses. Examples of human rights are the right to freedom of religion, the right to a fair trial when charged with a crime, the right not to be tortured, and the right to engage in political activity. These rights exist in morality and in law at the national and international levels. They are addressed primarily to governments, requiring compliance and enforcement (Nickel 2010: 1).

Penjelasan human rights sebagaimana di atas difokuskan kepada hak-hak manusia yang perlu diberikan ruang kebebasan dan perlindungan sama ada dari aspek politik, agama, perundangan dan sosial. Ia banyak berkisar bagi individu mahupun kelompokkelompok tertentu, seterusnya menggesa pihak pemerintah sebagai pelaksana yang sah dan memiliki kuasa eksekutif dalam memberikan kebebasan dan perlindungan kepada mereka. Umumnya, setiap manusia yang dilahirkan di muka bumi ini mempunyai hak dalam memastikan mereka berpeluang mendapatkan kehidupan yang lebih baik sehinggalah ke akhir hayat. Mereka ada hak untuk mendapatkan makanan, minuman, pakaian, tempat tinggal, kesihatan, pendidikan, pekerjaan, hubungan sosial, kedudukan, pangkat dan kemewahan.

Cuma kebelakangan ini, isu hak asasi manusia begitu banyak berkisar dari aspek politik, perundangan, kebebasan beragama dan hubungan sosial. Biarpun aspek alam sekitar turut diberikan perhatian oleh para pejuang 'hak asasi manusia', namun ia masih tidak mampu menyaingi populariti keempat-empat aspek tersebut yang kini begitu mendapat tempat di dunia Barat mahupun dunia Islam. Tidak dinafikan, antara faktor mengapa 'hak asasi manusia' semakin hari semakin mendapat sambutan menggalakkan, adalah disebabkan oleh slogan 'kebebasan' (freeedom) yang menjadi prinsip utama dalam 'hak asasi manusia'. Dari sudut sejarah tamadun Barat, slogan freedom merupakan salah satu faktor utama kepada kejayaan masyarakat Barat moden yang menggunakan 'kebebasan' akal mereka daripada dikongkong oleh kuasa gereja dalam menentukan hala tuju alam. 'Kebebasan' telah menyuntik mereka kepada semangat membangunkan sains dan teknologi moden, malah sebagai dasar kebangkitan era Renaisans.

Berbeza sekali dengan pandangan Nasr jika diajukan soalan kepadanya, adakah perjuangan atas nama 'hak asasi manusia' memberikan kebaikan terhadap alam sekitar? Bagi Nasr, 'hak asasi manusia' masih tidak mampu memastikan hak alam sekitar dapat dipertahankan selagi mana istilah human rights itu sendiri masih gagal difahami secara tepat. Ilmu makna (semantik) bagi perkataan human rights yang diperjuangkan oleh para pendukungnya pada hari ini adalah bersifat sekular iaitu terpisah daripada nilai agama. Walaupun peraturan alam begitu banyak dirangka dan dijelaskan oleh ajaran agama melalui kitab suci, namun masyarakat yang memperjuangkan 'hak asasi manusia' pada hari ini lebih selesa menggunakan sumber akal rasional semata-mata. Mereka beranggapan ia lebih saintifik, tambahan pula dibantu oleh kemajuan sains dan teknologi moden. Akhirnya, kedudukan alam tidak lagi dinilai dari sudut agama, tetapi diukur dari sudut manfaat penggunaannya kepada manusia. Ini dinyatakan oleh Nasr:

There is so much talk today of human rights, that is necessary to mention here the basic truth that according to the Islamic perspective, responsibilities precede rights. Man has no rights of his own independent of God, whether these rights be over nature or even over himself since he is not the creator of his own being. Man is not in fact capable of creating anything from nothing. The power of 'fiat lux' belongs to God alone. What rights man does possess is 
given to him by God as a consequence of his having accepted the covenant with God and fulfilled his responsibilities as God's vice-gerent on earth (Nasr 1990: 40).

Manusia telah menyalahgunakan 'kebebasan' (freedom) kerana mereka beranggapan masing-masing mempunyai hak dan perlindungan mutlak sebagaimana yang ditekankan melalui konsep 'hak asasi manusia'. Mereka sanggup mengenepikan prinsip agama dalam menjalani kehidupan ke atas alam. Menurut Nasr, dalam usaha menangani krisis alam sekitar, maka 'hak asasi kebenaran' sebagai manusia yang bertanggungjawab perlulah diutamakan berbanding 'hak asasi manusia'. 'Hak asasi manusia' pada hari ini adalah menjauhkan diri mereka daripada dianggap sebagai hamba Tuhan, sebaliknya mengagung-agungkan diri mereka sebagai makhluk yang paling layak membuat keputusan ke atas alam atas nama 'kebebasan'. Mereka telah menuntut pelbagai 'kebebasan' diri, seterusnya bertindak sesuka hati ke atas alam dengan panduan 'etika alam sekitar' ciptaan akal logik manusia, tanpa memikirkan kesan buruk terhadap alam sekitar dari sudut nilai agamanya. Bagi Nasr, masyarakat yang memperjuangkan 'hak asasi manusia' lebih menuntut 'kebebasan' diri berbanding 'tanggungjawab' diri sebagai seorang yang beragama dalam menjaga alam sekitar. Nilai alam sekitar di sisi mereka hanya diukur dari sudut manfaat penggunaannya, manakala agama pula dianggap sebagai perkara kedua.

Dalam agama Islam, Allah s.w.t telah memberikan peringatan agar umat manusia sesekali tidak menimbulkan bala bencana ciptaan mereka sendiri. Jika merujuk kepada kefahaman ayat al-Quran dalam surah al-Baqarah (2:205), Allah s.w.t menyeru umat manusia supaya tidak membuat sebarang kerosakan di muka bumi seperti membunuh manusia dan haiwan serta memusnahkan tumbuh-tumbuhan dengan mengikut hawa nafsu mereka yang tidak dikawali oleh agama. Sehubungan itu, agama diperlukan agar manusia hanya bertindak ke atas muka bumi melalui tingkah laku yang berperaturan dan terkawal.

Jika merujuk ke dalam agama Kristian sekalipun, sebagaimana kefahaman dalam kitab Injil (Bible) seperti Genesis (1:26-28), masyarakat Kristian dikehendaki menjadi pengurus alam sekitar yang baik dan sentiasa bertanggungjawab ke atas semua makhluk. Kegagalan mereka mengurus alam dengan baik bermakna ia adalah kegagalan mereka mematuhi arahan Tuhan. Justeru, agama melalui kitab sucinya telah menyediakan kerangka umum tentang peraturan alam agar manusia mampu melaksanakannya secara bijaksana demi memastikan hak alam sentiasa dihargai.

\section{Freedom (Kebebasan) sebagai Prinsip Utama Hak Asasi Manusia}

Walaupun pada asalnya istilah freedom (kebebasan) hanyalah untuk memperjuangkan kesaksamaan bagi setiap individu dan masyarakat, tetapi kebelakangan ini kewujudan pelbagai pertubuhan atas tujuan menambahkan lagi tuntutan-tuntutan 'hak asasi manusia', seakan-akan menenggelamkan pula fungsi agama dalam menggaris dan menghadkan tuntutan manusia yang sememangnya tidak pernah puas dengan apa yang ada. Inilah punca mengapa human rights (hak asasi manusia) menjadi salah satu perkataan penting yang perlu difahami konsepnya pada pandangan Nasr. Beliau mendapati kebanyakan nilai yang terdapat dalam pertubuhan-pertubuhan bersifat 'hak asasi manusia' adalah terlalu mengagungkan falsafah humanisme moden semata-mata sehingga garisan atau peraturan yang dijelaskan oleh agama tidak kelihatan. Nasr mengulas:

The second example is the question of human rights. Any value of this kind develops from a particular philosophy, it is not universal, it is culturally and 
philosophically bound. If you believe that God has created men and women, then they have no rights unless they fulfill their obligations to God (Nasr 1993: $35)$.

Setiap tindakan yang berasaskan 'hak asasi manusia' masa kini kebanyakannya berpegang kepada falsafah yang tidak bersifat sejagat iaitu dalam acuan modenisme. Justeru, sudah tentulah jalan penyelesaian yang dilaksanakan turut tidak sempurna termasuklah dalam isu menangani krisis alam sekitar. Menurutnya lagi, istilah freedom (kebebasan) yang diperjuangkan atas nama human rights dalam menyelamatkan alam merupakan langkah yang menghilangkan nilai kesucian alam. Konsep freedom membentuk falsafah humanisme iaitu falsafah yang meminggirkan agama dalam mengolah muka bumi. Falsafah tersebut menggalakkan manusia mengutamakan kebebasan akal rasional yang dianugerahkan oleh Tuhan dalam membuat sebarang keputusan ke atas alam berbanding keputusan berpandukan kitab suci yang juga dianugerahkan oleh Tuhan. Nasr menyebut:

... the new notion of freedom which may in fact be considered as the main element of Renaissance and the post Renaissance humanism. This new understanding of freedom mean essentially independence from the sacred world of Medieval Christianity and its cosmic order and not freedom from the limitations of the ego and the bonds of material existence as envisaged by seers and sages in East and West over the ages. ... They exalted man's freedom to form and change the world as he willed irrespective of any cosmic laws or even of the Divine Will, at least according to those who developed this idea later on the basis of the Renaissance humanistic notion of freedom. . . Man now becomes the independent protagonist in the cosmic drama and he, rather than "Fortune", is now seen to control and direct the ship of human life. . . . Humanistic Renaissance authors also tended to associate freedom with reason. A case in point is 'De libro arbitrio' of Lorenzo Valla, where freedom is judged from the point of view of reason and not religious dogma. Valla, in fact, insists that reason "is the best author" not to be contradicted by any other authority. He then goes on to criticize the sacred hierarchy of the Church and, despite accepting Christianity as a pure truth... There is thus created a link between the understanding of the notion of human freedom and rationalism, which dominated Western thought until the revolt against reason in nineteenthcentury Western Philosophy (Nasr 1996: 173).

Sejarah penggunaan istilah freedom (kebebasan) berhubung kait dengan penggunaan istilah independent yang juga bermaksud 'bebas' ataupun 'merdeka'. Walau bagaimanapun, Nasr tetap menganggap kedua-duanya sama. Freedom mahupun independent, telah menyebabkan manusia menghilangkan nilai kesucian yang terdapat pada alam. Zaman Pembaharuan yang disebut sebagai Renaisans, telah memberikan kesan negatif kepada pembentukan hala tuju kehidupan manusia. Konsep 'kebebasan' dianggap sebagai kuasa manusia melakukan segala aktiviti terhadap alam tanpa mengambil kira saranan agama dalam menjaganya.

Nasr juga mendapati, konsep freedom (kebebasan) mempunyai hubungan dengan rationalism (rasionalisme) sehingga membawa kepada pemahaman yang berpegang kepada humanisme moden. Dalam falsafah Barat, 'rasionalisme' merupakan aliran yang menekankan bahawa akal logik mesti diberi peranan utama sebagai sumber ilmu pengetahuan tentang alam (Bagus 2005: 929). Ada pendapat mengatakan, aliran tersebut 
tidak memerlukan bantuan inderawi (emperikal) dalam memahami alam kerana sudah memadai melakukan analisis akal logik, dan ada pula pendapat yang mengatakan ia saling memerlukan bantuan inderawi dalam memahami alam (Urmson \& Ree 1991: 272). Sekalipun penjelasan yang diberikan sama ada akal logik mahupun emperikal dalam memahami alam, ia adalah tertolak dalam pemikiran Nasr. Sebabnya, beliau begitu mementingkan sumber dari agama dalam memahami alam. Rasionalisme yang ada pada hari ini adalah pemahaman yang berpegang kepada falsafah humanisme moden.

Zaman Pembaharuan mempunyai sejarah kegemilangan di kalangan masyarakat Eropah sehingga melonjakkan revolusi industri di benua berkenaan. Namun, ia turut memberikan kesan negatif kepada penghayatan ajaran Kristian di Eropah tentang kepentingan penjagaan alam di kalangan penganutnya. Mereka menggunakan kelebihan 'kebebasan' diri yang bersumberkan akal logik dalam mengolah muka bumi, bukannya mengikuti dogma Kristian yang mengajarkan mereka agar dapat mengurus alam dengan baik.

Pada pandangan Nasr, untuk menemui semula kesucian alam, maka manusia perlu memahaminya dari sudut ilmu yang bersepadu iaitu bersumberkan agama (Nasr 1996: 271). Dalam konteks Islam, Nasr menegaskan bahawa manusia tidak boleh hanya menjadi khalifah semata-mata di muka bumi, tetapi juga sebagai hamba yang sentiasa taat kepada Tuhan yang menciptakannya. Ini diungkapkan oleh Nasr: “ . . you cannot be khalifatullah without being 'abdullah" (Nasr 1993: 35). Hal ini perlu ditekankan memandangkan semenjak era moden sehinggalah pascamoden, manusia telah menyalahgunakan 'kebebasan'. Mereka beranggapan masing-masing mempunyai kemutlakan kuasa akal rasional sebagaimana yang ditekankan melalui konsep 'hak asasi manusia'. Masyarakat juga merasakan bukannya sesuatu yang salah di sisi undang-undang sekiranya tidak merujuk kepada sumber agama dalam memahami alam, begitu juga dalam usaha untuk menyelamatkan alam sekitar. Demikian itulah mereka lebih fokus merujuk kepada 'etika alam sekitar' ciptaan sarjana dan saintis moden berbanding merujuk kepada agama ciptaan Tuhan.

Konsep 'kebebasan' yang terhasil atas nama 'hak asasi manusia' mempunyai sejarahnya tersendiri. Merujuk kepada The Holt Basic Dictionary of American English, perkataan freedom (kebebasan) turut diistilahkan sebagai " . . a man freed from slavery" (Walters 1966: 299). Slavery bermaksud 'pengabdian' iaitu daripada perkataan slave (hamba abdi). Ia memberi gambaran bahawa manusia perlu membebaskan diri mereka daripada perhambaan. Namun begitu, perlu difahami bahawa manusia masih lagi golongan hamba kerana mereka masih mempunyai Tuannya iaitu Tuhan. Oleh itu, seseorang itu mempunyai hak untuk membebaskan diri daripada menjadi hamba kepada orang lain. Akan tetapi, itu tidak bermakna dia juga ada hak untuk membebaskan dirinya daripada menjadi hamba kepada Tuhan. Jika merujuk kepada agama Islam, didapati manusia adalah dilantik sebagai khalifah di muka bumi dan pada masa yang sama juga, mereka masih perlu memperakui diri sebagai hamba, bahkan adalah wajib untuk sentiasa taat kepada perintah Allah s.w.t di muka bumi melalui amalan-amalan bersifat pengabdian (slavery). Justeru, tiada istilah 'kebebasan' mutlak bagi manusia untuk melakukan segala aktiviti ke atas alam melainkan di bawah peraturan-peraturan Allah s.w.t.

Menurut Seyyed Hossein Nasr, anugerah 'kebebasan' manusia yang merosakkan alam sekitar sebenarnya berpunca daripada pemahaman sekular. Maksudnya, ia dipengaruhi oleh mentaliti masyarakat yang telah terperangkap dalam peraturan ekonomi global (Nasr 1996: 208). Peraturan ekonomi global pula adalah diciptakan oleh akal logik manusia sendiri dalam menguasai sumber alam. Apabila masyarakat telah terperangkap dalam peraturan tersebut, akhirnya telah membentuk mentaliti untuk menerima bahawa 
krisis alam sekitar adalah tidak dapat dielakkan kerana sebagai kesan lumrah kehidupan masyarakat yang ingin mendapatkan kehidupan yang lebih baik atas nama thak asasi manusia'.

Suara 'kebebasan' dalam 'hak asasi manusia' yang diperjuangkan oleh kebanyakan masyarakat masa kini dikatakan semakin melampau dan keterlaluan. Malah, masih tidak nampak kemampuan 'hak asasi manusia' untuk menyelesaikan krisis alam sekitar selagi mana tertakluk secara mutlak kepada akal rasional dan kehendak hawa nafsu manusia semata-mata. Terlalu banyak tuntutan yang dibuat oleh pelbagai lapisan masyarakat. Isu yang diperjuangkan oleh mereka selalunya disandarkan kepada alasan 'memenuhi tuntutan hak asasi manusia'. Mereka juga menyumbang ke arah penghabisan sumber alam kerana merasakan ada hak dan kebebasan untuk mendapatkannya biarpun sehingga kepada tahap mendominasi dan memanipulasi sumber alam, asalkan dapat memenuhi tuntutan hawa nafsu dan hedonisme, bukan lagi hak asasi. Selagi mana sumber alam masih boleh diperolehi, maka selagi itulah ia dituntut oleh manusia untuk mendapatkannya atas nama 'hak asasi manusia'. Mereka merasakan berhak menebang kawasan hutan dengan alasan untuk mendirikan kawasan perumahan dan perniagaan. Mereka jugalah yang sentiasa melipatgandakan proses pengeluaran bahan mentah berasaskan sumber alam melalui alasan 'wujudnya permintaan yang tinggi'. Jadi, bagaimanakah para pendukung 'hak asasi manusia' itu berupaya menangani krisis alam sekitar sedangkan mereka begitu mengutamakan 'diri sendiri' dalam menggunakan sumber alam berbanding menyelamatkan hak alam? Malah, agak amat jarang sekali kedengaran bahawa sesuatu permintaan manusia dalam menggunakan sumber alam adalah diperjuangkan atas nama memenuhi tuntutan agama.

Masyarakat masa kini merasakan mereka ada hak dan kebebasan untuk mendapatkan banyak kenderaan mewah walaupun akan menyumbang kepada pencemaran bunyi dan kualiti udara. Mereka juga merasakan ada hak dan kebebasan untuk mendirikan rumah kediaman mewah di puncak bukit, pinggir hutan mahupun kawasan gunung biarpun tempat-tempat tersebut sebenarnya amat sesuai bagi hidupan liar. Jadi, inikah yang dikatakan perjuangan 'hak asasi manusia' betul-betul membantu menangani krisis alam sekitar? Pada hari ini, gerakan yang bersifat hak asasi manusia semakin cuba membebaskan diri mereka daripada sebarang peraturan yang mereka rasakan menghalang pembangunan dan kemajuan diri. Setelah dunia mengalami proses kemodenan, didapati unsur agama semakin kurang mendapat tempat di sisi masyarakat dalam memakmurkan alam sekitar walaupun atas tiket 'hak asasi manusia'. Alam secara ilmu asalnya adalah tidak pernah terpisah daripada agama. Penekanan alam sebagai sesuatu yang suci memberikan gambaran jelas bahawa Seyyed Hossein Nasr meletakkan nilai yang tinggi kedudukan alam di sisi beliau. Alam merupakan anugerah suci kerana diciptakan oleh Tuhan Yang Maha Suci. Justeru, manusia tidak boleh merosakkan alam kerana hilangnya nilai kesucian alam bermakna manusia telah menghilangkan kesucian hubungan antara alam dengan Tuhan. Untuk mengekalkan kesucian alam, sudah tentunya memerlukan peraturan suci iaitu kerangka peraturan alam yang dibekalkan oleh agama melalui kitab suci. Sebab itulah agama penting kepada manusia untuk memastikan alam itu sentiasa terpelihara dengan kesucian kejadiannya. Malang sekali, didapati ramai di kalangan manusia yang sering memperjuangkan hak alam sekitar tanpa menggunakan dasar agama. Falsafah yang terkandung dalam 'hak asasi manusia' merupakan falsafah humanisme moden yang tidak sejagat. Maka, sudah tentulah pendekatan menangani krisis alam sekitar tidak akan berlaku dalam skop yang menyeluruh. Hal sebegini berlaku kerana mereka mula-mula sekali telah berpegang teguh dengan prinsip 'kebebasan' berbanding 'kebenaran' dalam memahami 'hak asasi manusia'. Perlu diketahui, istilah 'kebebasan' juga semakin berkembang 
maksudnya. Masyarakat tradisional memahami 'kebebasan' dalam beragama sebagai merujuk kepada kebebasan memilih mana-mana agama untuk dianuti. Namun, semenjak dunia mengalami era Renaisans yang terkenal dalam sejarah masyarakat moden di samping kemunculan revolusi industri, istilah 'kebebasan' dalam beragama boleh juga dirujuk sebagai membebaskan diri daripada ikatan agama. Dengan kata lain, ia juga dimaksudkan sebagai meminggirkan agama ataupun menolak agama, malah lebih tepat lagi dimaknakan juga sebagai tidak perlu menganuti mana-mana agama (ateisme). Inilah krisis nilai manusia yang menyumbang kepada krisis alam sekitar. Justeru, tiada 'kebebasan mutlak' bagi setiap manusia kerana mereka masih lagi hamba kepada Tuhan sehingga ke akhir hayat mereka. Dengan kata lain, tiada 'kebebasan' mutlak bagi umat manusia dalam menentukan hala tuju alam sekitar. Sebaliknya 'kebebasan' manusia sebagai khalifah adalah masih terikat kemas dengan 'ketaatan' mereka sebagai hamba kepada Tuhan.

\section{References}

Azwani Abdul Rahman. 2010. Pelanggaran Hak Asasi Manusia dalam Perubahan Iklim. KonsumerKINI, (atas talian) http://www.konsumerkini.net.my/v1/index.php/ berita-terkini/hak-asasi-manusia/363-pelanggaran-hak-asasi-manusia-dalamperubahan-iklim. Diakses pada 30 July 2012.

Bagus, Lorens. 2005. Kamus Filsafat. Jakarta: Penerbit PT Gramedia Pustaka Utama.

Foon Weng Lian. 2012. Suhu Tinggi Menyebabkan Corak Hujan yang Melampau di Kawasan Tropikal. KonsumerKINI, (atas talian) http://www.konsumerkini.net.my/v1/index. php/berita-terkini/perubahan-iklim/787-suhu-tinggi-menyebabkan-corak-hujanyang-melampau-di-kawasan-tropikal. Diakses pada 5 November 2012.

Nasr, Seyyed Hossein. 1990. Islam and the Environmental Crisis. MAAS Journal of Islamic Science 6(2): 31-51.

Nasr, Seyyed Hossein. 1993. Islam and the Challenge of the 21st Century. Kuala Lumpur: Dewan Bahasa dan Pustaka.

Nasr, Seyyed Hossein. 1996. Religion and the Order of Nature. New York: Oxford University Press.

Nickel, James. 2010. Human Rights. Standford Encyclopedia of Philosophy, (atas talian) http://plato.stanford.edu/entries/rights-human. Diakses pada 27 July 2012.

Noresah Baharom (pnyt.). 2007. Kamus Dewan. Ed. ke-4. Kuala Lumpur: Dewan Bahasa dan Pustaka.

Office of the United Nations High Commissioner for Human Rights. 2002. Meeting of Experts on Human Rights and the Environment, (atas talian) http://www2 .ohchr.org/english/issues/environment/environ/conclusions.htm. Diakses pada 30 July 2012.

Office of the United Nations High Commissioner for Human Rights. 2004. ABC: Teaching Human Rights - Practical Activities for Primary and Secondary Schools. New York: United Nations.

Office of the United Nations High Commissioner for Human Rights. 2007. Human Rights and the Environment, (atas talian) http://www2.ohchr.org/english/issues/environment /environ/index.htm. Diakses pada 30 July 2012.

United Nations Environment Programme t.th. High Level Expert Meeting on the New Future of Human Rights and Environment: Moving the Global Agenda Forward (atas talian) http://www.unep.org/environmentalgovernance/Events/HumanRightsandEnviron ment/tabid/2046/language/en-US/Default.aspx. Diakses pada 28 July 2012. 
Urmson, J.O. \& Ree, Jonathan (pnyt.). 1991. The Concise Encyclopedia of Western Philosophy \& Philosophers. London: Routledge.

Walters, Morgan L. (pnyt.). 1966. The Holt Basic Dictionary of American English. New York: Holt, Rinehart and Winston, Inc.

Wood, Kurt A. 2006. The Scientific Exegesis of the Qur'an: A Systematic Look. Dlm. Rais Ahmad (pnyt.). Islam and Scientific Debate: Searching for Legitimacy, h. 87-104. New Delhi: Global Vision publishing House. 